\title{
Mechanism of cell cycle arrest and apoptosis induction by conjugated eicosapentaenoic acid, which is a mammalian DNA polymerase and topoisomerase inhibitor
}

\author{
YUKO YONEZAWA ${ }^{1}$, TAKAHIKO HADA ${ }^{2}$, KEISUKE URYU $^{2}$, TSUYOSHI TSUZUKI ${ }^{3}$, KIYOTAKA NAKAGAWA ${ }^{4}$, \\ TERUO MIYAZAWA ${ }^{4}$, HIROMI YOSHIDA ${ }^{1,5}$ and YOSHIYUKI MIZUSHINA ${ }^{1,5}$ \\ ${ }^{1}$ Laboratory of Food \& Nutritional Sciences, Department of Nutritional Science, Kobe-Gakuin University, \\ Nishi-ku, Kobe, Hyogo 651-2180; ${ }^{2}$ Department of Research and Development, Bizen Chemical Co. Ltd., \\ Kumayama-cho, Akaiwa, Okayama 709-0716; ${ }^{3}$ Department of Food Management, School of Food, \\ Agricultural and Environment Sciences, Miyagi University, Sendai 982-0215; ${ }^{4}$ Food and Biodynamic \\ Chemistry Laboratory, Graduate School of Life Science and Agriculture, Tohoku University, Sendai 981-8555; \\ ${ }^{5}$ Cooperative Research Center of Life Sciences, Kobe-Gakuin University, Nishi-ku, Kobe, Hyogo 651-2180, Japan
}

Received December 11, 2006; Accepted January 30, 2007

\begin{abstract}
Conjugated eicosapentaenoic acid (cEPA) selectively inhibited the activities of mammalian DNA polymerases (pols) and human DNA topoisomerases (topos). cEPA inhibited the cell growth of two human leukemia cell lines, NALM-6, which is a p53-wild type, and HL-60, which is a p53-null mutant, with $\mathrm{LD}_{50}$ values of 37.5 and $12.5 \mu \mathrm{M}$, respectively. In both cell lines, cEPA arrested in the G1 phase, and increased cyclin E protein levels, indicating that it blocks the primary step of in vivo DNA replication by inhibiting the activity of replicative pols rather than topos. DNA replication-related proteins such as RPA70, ATR and phosphorylated-Chk1/2 were increased by cEPA treatment in the cell lines, suggesting that cEPA led to DNA replication fork stress inhibiting the activities of pols and topos, and the ATR-dependent DNA damage response pathway could respond to the inhibitor of DNA replication. The compound induced cell apoptosis
\end{abstract}

Correspondence to: Dr Yoshiyuki Mizushina, Laboratory of Food \& Nutritional Sciences, Department of Nutritional Science, Kobe-Gakuin University, Nishi-ku, Kobe, Hyogo 651-2180, Japan

E-mail: mizushin@nutr.kobegakuin.ac.jp

Abbreviations: EPA, eicosapentaenoic acid; cEPA, conjugated EPA; PUFA, polyunsaturated fatty acid; pol, DNA polymerase (EC 2.7.7.7); topo, DNA topoisomerase; ATR, ataxia-telangiectasia mutated- and Rad3-related protein kinase; ATRIP, ATR-interacting protein; cdk, cyclin-dependent kinase; dTTP, 2'-deoxythymidine 5'-triphosphate; dsDNA, double-stranded DNA; ssDNA, singlestranded DNA; RPA, replication protein A; MTT = 3-(4,5-dimethylthiazol-2-yl)-2,5-diphenyl-2 $\mathrm{H}$-tetrazolium bromide

Key words: conjugated eicosapentaenoic acid, DNA polymerase, DNA topoisomerase, enzyme inhibitor, DNA replication, cell proliferation, cell cycle arrest, p53, apoptosis through both p53-dependent and p53-independent pathways in cell lines NALM-6 and HL-60, respectively. These results suggested the therapeutic potential of cEPA as a leading anticancer compound that inhibited activities of pols and topos.

\section{Introduction}

Both DNA polymerases (pols) and DNA topoisomerases (topos) have recently emerged as important cellular targets for chemical intervention in the development of anti-cancer agents. Pol catalyzes the addition of deoxyribonucleotides to the 3'-hydroxyl terminus of primed double-stranded DNA molecules (1), and topo catalyzes the concerted breaking and rejoining of DNA strands and is involved in producing the necessary topological and conformational changes in DNA $(1,2)$. Therefore, there are no enzymatic similarities between the two enzymes, although they are both critical to many cellular processes such as DNA replication, repair and recombination, and may act in harmony with each other.

We have screened for pol inhibitors $(3,4)$, and found that mammalian pols $\alpha$ and $\beta$ are inhibited by linear-chain fatty acids with the following characteristics: a hydrocarbon chain containing 18 or more carbons, a free carboxyl end, and double bonds with the cis-configuration, n-3 polyunsaturated fatty acid (PUFA) having the strongest inhibitory effect of any fatty acid tested $(4,5)$. These fatty acids also inhibit the activities of human topos I and II (6). Epidemiological data indicate that consumption of fish oil rich in PUFA correlates with a reduced incidence of colon cancer (7). Experimental studies indicate that fish oil plays a protective role in mice (8) and rats (9) and that perilla oil rich in n-3 PUFA ( $\alpha$-linolenic acid) inhibits colon carcinogenesis in rats (10). n-3 PUFAs seem to be particularly important in the inhibition of colon carcinogenesis. Eicosapentaenoic acid (EPA; 5Z8Z11Z14Z17Z20:5) and docosahexanoic acid (DHA; 4Z7Z10Z13Z16Z19Z22:6), both n-3 PUFAs, exert significant inhibitory effects on colon carcinoma cell growth at the primary site and metastases 
$(11,12)$; however, it is unclear which class of n-3 PUFA is more potent in suppressing colon carcinogenesis.

Conjugated fatty acids are positional and geometrical isomers with several conjugated double bonds. One of these, conjugated linoleic acid (cLA), is found in meat from ruminants and in dairy products (13) and reportedly reduces colon cancer risk in rats (14). cLA also reportedly inhibits the growth of human colon cancer cells in culture $(15,16)$. As linoleic acid, an n-6 PUFA, accelerates the growth of colon cancer cells (12), the opposite effect of cLA is of particular interest. As n-3 PUFAs have been shown to have anticarcinogenic activity, conjugated fatty acids converted from n-3 PUFAs may show higher tumor-inhibiting activity than cLA or n-3 PUFAs themselves. Fatty acids with conjugated double bonds exist in nature: seaweeds such as red and green algae contain highly n-3 unsaturated conjugated fatty acids, i.e., conjugated EPA (cEPA; 5Z7E9E14Z17Z20:5), bosseopentaenoic acid (5Z8Z10E12E14Z-20:5) and stellaheptaenoic acid (4Z7Z9E11E13Z16Z19Z-22:7) (17,18). We previously realized the importance of the two classes of n-3 PUFA; EPA and DHA, normal and conjugated, and the inhibitory effect of cEPA on both pols and topos was stronger than that of cDHA (19). Thus, conjugated cEPA seems to be an ideal model for the study not only of the molecular mechanisms that inhibit activities of pols and topos for the development of new anticancer drugs, but also of cellular proliferation processes such as DNA replication.

In this study, we examined the involvement of cEPA in cell cycle regulation and apoptosis in p53-wild and null mutant of human cancer cell lines. We demonstrated that cEPA induces cell cycle arrest at G1 phase arrest and apoptosis mediated by both p53-dependent and p53-independent pathways, and suggested that the cell cycle is tightly regulated by DNA damage-response proteins including the ATR-Chk1/2 pathway.

\section{Materials and methods}

Materials. EPA was purchased from Nu-Chek Prep Inc. (Elysian, MN, USA). Nucleotides and chemically synthesized DNA template-primers such as poly(dA) and oligo $(\mathrm{dT})_{12-18}$, and radioisotope reagents such as $\left[{ }^{3} \mathrm{H}\right]$-dTTP (2'-deoxythymidine 5'-triphosphate) (43 Ci/mmol) were purchased from GE Healthcare Bio-Science Corp. (Piscataway, NJ, USA). All other reagents were of analytical grade and purchased from Nacalai Tesque Inc. (Kyoto, Japan). Two human leukemia cell lines, HL-60, which is a p53-null mutant (IFO50022), and NALM-6, which has a high expression level of p53 (TKG0413) (20), were supplied by the Health Science Research Resources Bank (Osaka, Japan) and the Cell Resource Center for Biomedical Research, Tohoku University (Sendai, Japan), respectively.

Preparation of cEPA by alkaline treatment. cEPA was prepared by alkaline treatment following the AOAC method with slight modifications (21). Potassium hydroxide at a concentration of 6.6 or $21 \%(\mathrm{w} / \mathrm{w})$ in ethylene glycol was prepared and the $\mathrm{KOH}$ solution was bubbled for $5 \mathrm{~min}$ with nitrogen gas. Ten milligrams of EPA or DHA were added to $1 \mathrm{ml}$ of $6.6 \%$ or $21 \% \mathrm{KOH}$ solution in a test tube $(10 \mathrm{ml}$ volume $)$. The mixture was bubbled with nitrogen gas and then screw-capped and allowed to stand for 5 or $10 \mathrm{~min}$ at $180^{\circ} \mathrm{C}$. The reaction mixture was cooled, and $1 \mathrm{ml}$ of methanol was added. The mixture was acidified to below pH 2.0 with $2 \mathrm{ml}$ of $6 \mathrm{~N} \mathrm{HCl}$. After dilution with $2 \mathrm{ml}$ of distilled water, the conjugated fatty acid was extracted with $5 \mathrm{ml}$ of hexane. The hexane extract was then washed with $3 \mathrm{ml}$ of $30 \%$ methanol and with $3 \mathrm{ml}$ of distilled water before being evaporated under a nitrogen gas stream. The conjugated fatty acids were stored at $-20^{\circ} \mathrm{C}$ after being purged with nitrogen gas. UV/VIS spectrophotometric analysis was performed with a Shimadzu UV-2400PC. Spectrophotometric readings confirmed the conjugation of fatty acids of pentaene $(345 \mathrm{~nm})(21,22)$. cEPA was dissolved in dimethyl sulfoxide (DMSO) at various concentrations and sonicated for $30 \mathrm{sec}$.

Enzymes. Pol $\alpha$ was purified from calf thymus by immunoaffinity column chromatography as described previously (23). Recombinant rat pol $\beta$ was purified from E. coli JMpß5 as described by Date et al (24). The human pol $\gamma$ catalytic gene was cloned into pFastBac. Histidine-tagged enzymes were expressed using the BAC-TO-BAC HT Baculovirus Expression System according to the supplier's manual (Life Technologies, MD, USA) and purified using ProBoundresin (Invitrogen Japan, Tokyo Japan) (25). Human pol $\delta$ and $\varepsilon$ were purified from the nuclear fraction of human peripheral blood cancer cells (Molt-4) using the second subunit of pol $\delta$ and $\varepsilon$-conjugated affinity column chromatography, respectively (26). Human recombinant DNA topoisomerases I and II $\alpha$ (topos I and II) $(2 \mathrm{U} / \mu \mathrm{l})$ were purchased from TopoGen, Inc. (Columbus, $\mathrm{OH}, \mathrm{USA})$.

Enzyme assays. Activities of mammalian pols were measured using methods described previously $(4,5)$. Poly $(\mathrm{dA}) /$ oligo(dT $)_{12-18}$ and dTTP were used as the DNA template-primer and nucleotide substrate, respectively. One unit of pol activity was defined as the amount of enzyme that catalyzed the incorporation of $1 \mathrm{nmol}$ of dNTP (2'-deoxyribonucleotide 5'triphosphate, i.e. dTTP) into synthetic DNA template-primers (i.e. $\operatorname{poly}(\mathrm{dA}) /$ oligo $(\mathrm{dT})_{12-18}, \mathrm{~A} / \mathrm{T}=2 / 1$ ) in $60 \mathrm{~min}$ at $37^{\circ} \mathrm{C}$ under normal reaction conditions for each enzyme $(4,5)$. Human topos I and II were measured using standard assays according to Lui and Miller (27). Activity without the inhibitor was considered to be $100 \%$, and the remaining activity at each inhibitor concentration was determined relative to this value.

Investigation of cytotoxicity in cultured cells. NALM-6 cells and HL-60 cells were cultured in RPMI-1640 medium supplemented with heat-inactivated $10 \%$ fetal bovine serum, sodium bicarbonate $(2 \mathrm{~g} / \mathrm{l})$ and streptomycin $(100 \mu \mathrm{g} / \mathrm{ml})$ at $37^{\circ} \mathrm{C}$ in a humidified atmosphere of $5 \% \quad \mathrm{CO}_{2} / 95 \%$ air. For the cell viability assay, cells were seeded in 96-well plates at a density of $1 \times 10^{4}$ cells per well with various concentrations of cEPA. These were dissolved in DMSO at a concentration of $30 \mathrm{mM}$ as a stock solution. The stock solution was diluted to various concentrations with growth medium and applied to each well. After incubation for $24 \mathrm{~h}$, the survival rate was determined by MTT [3-(4,5-dimethylthiazol-2-yl)-2,5-diphenyl tetrazolium bromide] assay (28).

Cell cycle analysis. NALM-6 and HL-60 cells ( $3 \times 10^{5}$ cells in 35-mm dish) were collected by centrifugation. 4', 6-diamidino- 
2-phenylindole (DAPI) was used to stain the DNA of individual nuclei by 'Cystain DNA 1 steps' kit (Partec; Munster, Germany). The DNA content of 10,000 stained cells was analyzed using a Partec Cell Counter Analyser (CCA Model; Partec) with Multicucle 3.11 software (Phoenix Flow Systems; San Diego, CA, USA). The cell debris and fixation artifacts were gated out.

Antibodies. Antibodies for Western blotting to the following antigens were obtained as indicated: p53, Chk1-P (phosphorylated form of Chk1-Ser345), Chk2-P (phosphorylated form of Chk2-Thr68) and p21 were from Cell Signaling Technology (Beverly, MA, USA); total Chk2, Cdc25A, cyclin A, cyclin B and cyclin E were from Neo Markers (Fremont, CA, USA); ATR, RPA70 and total Chk1 were from Santa Cruz (CA, USA); p53-P (phosphorylated form of p53-Ser15) and B-actin were from R\&D Systems Ltd. (Minneapolis, MN, USA).

Western blot analysis. The cells were lysed in RIPA buffer [50 mM Tris-HCl (pH 7.2), 150 mM EDTA, 1\% Nonidet P-40, $0.05 \%$ sodium dodecyl sulfate (SDS), $1 \mathrm{mM}$ PMSF and $1 \mathrm{mM}$ leupeptin]. Cell lysates were centrifuged at 14,000 x $\mathrm{g}$ for $10 \mathrm{~min}$ at $4^{\circ} \mathrm{C}$. The supernatant was analyzed by SDS-PAGE, then blotted onto a polyvinyldenefluoride (PVDF) membrane. The blots were subsequently incubated with the desired primary antibody.

Detection of apoptosis induced by cEPA. To analyze DNA ladder formation on treatment with cEPA, HL-60 cells and NALM-6 cells were washed twice with PBS. Cells $\left(1 \times 10^{6}\right)$ were lysed with $10 \mathrm{mM}$ Tris- $\mathrm{HCl}$ ( $\mathrm{pH} 7.4$ ) containing 10 mM EDTA, $0.5 \%$ Triton $\mathrm{X}-100$ and Rnase A $(0.2 \mathrm{mg} / \mathrm{ml})$, incubated at $37^{\circ} \mathrm{C}$ for $1 \mathrm{~h}$, and digested with proteinase $\mathrm{K}(0.5 \mathrm{mg} / \mathrm{ml})$ at $50^{\circ} \mathrm{C}$ for $30 \mathrm{~min}$. After the addition of a $1 / 2 \mathrm{Vol}$ of $10 \mathrm{M}$ ammonium acetate, the DNA was precipitated with $2.5 \mathrm{Vol}$ of ethanol, dissolved in gel loading buffer [40 mM Tris- $5 \mathrm{mM}$ sodium acetate-1 mM EDTA ( $\mathrm{pH} 7.8)$ ] and separated by electrophoresis in a $1.5 \%$ agarose gel. The gel was stained with ethidium bromide, and the DNA bands were visualized under UV light.

\section{Results}

Effects of cEPA on mammalian pols, human topos and other DNA metabolic enzymes. Table I shows $\mathrm{IC}_{50}$ values of cEPA for mammalian pols such as replicative pols $\alpha, \delta$ and $\varepsilon$, repair-related pol $\beta$, and mitochondrial pol $\gamma$, and human topos I and II. The compound dose-dependently inhibited the activities of five pols observed at 11.0-31.8 $\mu \mathrm{M}$, and the inhibitory effect on human pol $\gamma$ was the strongest in the pols tested. The inhibitory effect of cEPA was stronger than that of aphidicolin (29) or dideoxyTTP (30), well-known inhibitors of pol $\alpha$ and pol $\beta$, respectively. cEPA also significantly inhibited the activities of human topos I and II with $\mathrm{IC}_{50}$ values of 0.5 and $2.5 \mu \mathrm{M}$, respectively. Therefore, cEPA was a $>$ 4-fold stronger topo inhibitor than pol inhibitor.

cEPA had little inhibitory effect on the activities of higher plant (cauliflower) pols I ( $\alpha$-like pol) and II ( $\beta$-like pol), prokaryotic pols such as the Klenow fragment of $E$. coli
Table I. $\mathrm{IC}_{50}$ values of cEPA on the activities of mammalian DNA polymerases and human DNA topoisomerases.

\begin{tabular}{lc}
\hline Enzyme & $\mathrm{IC}_{50}$ values $(\mu \mathrm{M})$ \\
\hline Mammalian DNA polymerases & \\
Calf pol $\alpha$ & 14.5 \\
Rat pol $\beta$ & 31.6 \\
Human pol $\gamma$ & 11.0 \\
Human pol $\delta$ & 31.8 \\
Human pol $\varepsilon$ & 27.4 \\
& \\
Human DNA topoisomerases & \\
Topo I & 0.5 \\
Topo II & 2.5 \\
\hline
\end{tabular}

Each reaction mixture of pols and topos contained $0.05 \mathrm{U}$ of enzyme. The enzymatic activity was measured as described in Materials and methods. Enzyme activity in the absence of the compound was taken as $100 \%$.

pol I, Taq pol and T4 pol, and DNA metabolic enzymes such as DNA primase of calf pol $\alpha$, T7 RNA polymerase, T4 polynucleotide kinase, and bovine deoxyribonuclease I (data not shown).

To determine whether the inhibitor resulted in binding to DNA or enzyme, the interaction of cEPA with double-stranded DNA (dsDNA) was investigated based on the thermal transition of dsDNA with or without cEPA. The Tm of dsDNA with an excess amount of cEPA $(100 \mu \mathrm{M})$ was measured using a spectrophotometer equipped with a thermoelectric cell holder. In the concentration range used, no thermal transition of Tm was observed, whereas ethidium bromide used as a positive control, a typical intercalating compound, produced a clear thermal transition (data not shown). These results indicated that cEPA did not intercalate to DNA as a substrate, and the compound might directly bind to the enzymes (i.e., pols and topos) and inhibit their activities.

Therefore, cEPA might be a potent inhibitor of mammalian pols and topos, which could be molecular targets for anticancer chemotherapy. We therefore investigated the mechanism of the inhibitory effect of cEPA on human cancer cells.

Effects of cEPA on inhibition of human cancer cell growth. To determine the effects of cEPA on cultured human cancer cells, we tested their influence on cell growth in two leukemia cell lines, NALM-6 and HL-60. NALM-6 is a normal cell line which has a p53 gene, and HL-60 is a mutant cell line which has a p53 gene deletion. As shown in Fig. 1, cEPA efficiently inhibited cell growth of both NALM-6 and HL-60 in a dose-dependent manner. After $24 \mathrm{~h}$ of treatment, the $\mathrm{LD}_{50}$ values of cEPA on NALM- 6 and HL-60 cells were 37.5 and $12.5 \mu \mathrm{M}$, respectively. Since the cell growth effect of cEPA on the HL-60 cell line was more cytotoxic than that on the NALM-6 cell line, p53 protein expression must be related to cell growth inhibition by cEPA, which is a selective inhibitor of pols and topos. The inhibitory concentrations of cell growth 


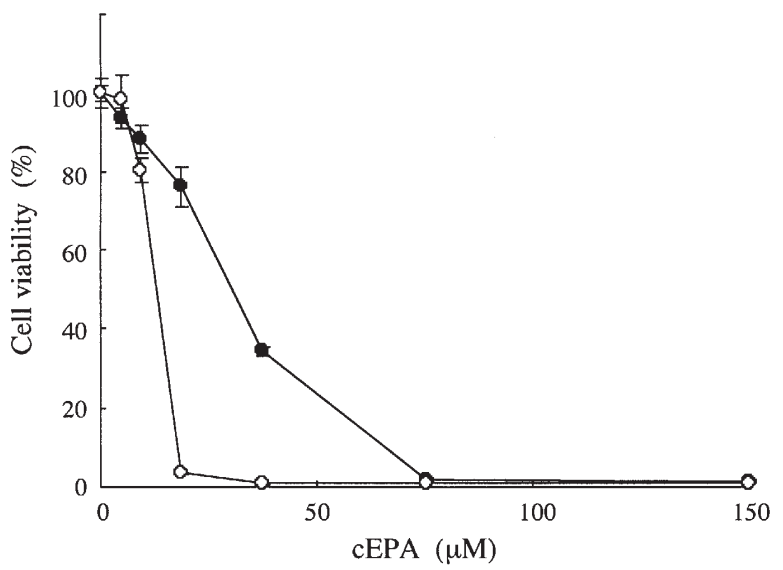

Figure 1. Effect of cEPA on the proliferation of a human cancer cell line. The data show the dose-response curves of the growth inhibition of human leukemia cell lines, NALM-6 of p53-wild type (closed circle) and HL-60 of p53-null mutant (open circle) incubated with various concentrations of cEPA for $24 \mathrm{~h}$. Cell proliferation was determined by MTT assay (47). Values are shown as the means \pm SEM of three independent experiments.

were almost the same as the inhibitory effect of mammalian pols rather than topos. We investigated in more detail which inhibition by cEPA is effective for cancer cell proliferation, that of pols or topos.

Effects on the cell cycle progression of cEPA. Next, we analyzed whether cEPA affected the cell cycle distribution of cEPA-treated cells (Fig. 2). The cell cycle fraction was recorded after $24 \mathrm{~h}$ of treatment with the $\mathrm{LD}_{50}$ value of cEPA, and was compared with cells incubated in medium alone. The ratio of the three phases (i.e., G1, S and G2/M) in the cell cycle is shown in Fig. 2A. Consequently, among NALM-6 cells, which have the p53 gene, treated with $37.5 \mu \mathrm{M}$ cEPA, the population of cells in the G1 phase increased significantly (32.9 to $47.6 \%$ ), and the percentage of cells in the $S$ phase decreased from 53.8 to $37.1 \%$. Similarly, HL-60 cells, which do not have the p53 gene, clearly increased in the G1 phase (32.9 to $46.5 \%$ ), and decreased in the $\mathrm{S}$ and $\mathrm{G} 2 / \mathrm{M}$ phases (53.8\% to $44.6 \%$ and $13.3 \%$ to $8.9 \%$, respectively) when treated with $12.5 \mu \mathrm{M}$ cEPA. These results suggested that the actions of cEPA block from G1 to an early stage of the $\mathrm{S}$ phase in both NALM-6 and HL-60 cells, and p53 protein in the cells might not be effective for cell cycle regulation. Dehydroaltenusin, which is a specific pol $\alpha$ inhibitor, inhibited the cell cycle in the $\mathrm{S}$ phase (31), and classical topo inhibitors such as etoposide arrested the cell cycle in the G2 phase (32). cEPA, therefore, might be more effective in the inhibition of pols than topos in the cell, although cEPA inhibited the activities of mammalian pols and human topos, and the inhibitory effect for topos was stronger than that for pols in vitro (Table I).

We examined whether the cell cycle effect of cEPA was associated with the expression of cyclin proteins using Western blotting. Cyclin E protein is present from the end of the G1 to early $\mathrm{S}$ phase, and cyclin A protein keeps accumulating from the $\mathrm{G} 1$ to $\mathrm{S}$ phase $(33,34)$. It was suggested that cyclins $\mathrm{A}$ and $\mathrm{E}$ link the transition mechanism from the G1 to S phase, and appear when the cells start to synthesize DNA $(33,34)$.
(A)

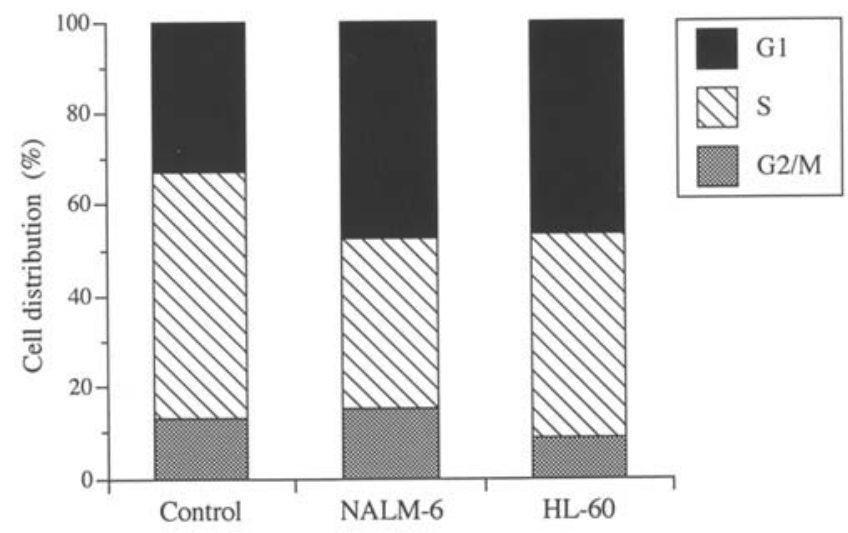

(B)

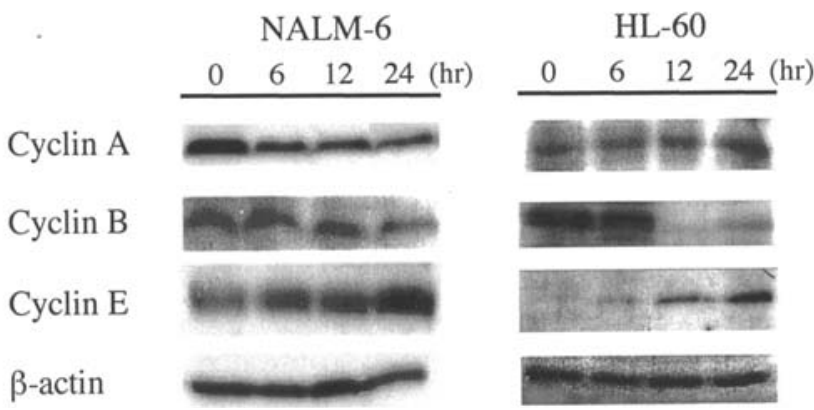

Figure 2. The effect of cEPA on the cell cycle. (A) Flow cytometric analysis of NALM-6 cells and HL-60 cells were incubated without (control) or with the $\mathrm{LD}_{50}$ values of cEPA (i.e., 37.5 and $12.5 \mu \mathrm{M}$, respectively) for $24 \mathrm{~h}$. Cell cycle distribution was calculated as the percentage of cells in the G1, S and G2/M phase. All experiments were performed three times. (B) Cyclin expression was analyzed using Western blotting. NALM-6 and HL-60 cell extracts of the nuclear fraction were prepared from cells treated with the $\mathrm{LD}_{50}$ values of cEPA. Cyclin A, B, E and ß-actin (control) were detected with specific antibodies.

On the other hand, cyclin B was associated with the mechanism of G2/M transition (34). As shown in Fig. 2B, the expression of cyclin A proteins did not change and slightly increased with the $\mathrm{LD}_{50}$ value of cEPA treatment in NALM-6 cells and HL-60 cells, respectively. On the other hand, cyclin E proteins strongly increased, but cyclin B significantly decreased in both cell lines. These results suggested that cEPA induced and reduced the protein expression of cyclin $\mathrm{E}$ and cyclin $\mathrm{B}$, respectively, in human cancer cells with or without $\mathrm{p} 53$, and then the cyclins arrested human cancer cells in the G1/S phase. The inhibition of activities of pols and topos by cEPA might lead to the translation of cyclin proteins.

Effect on protein expression of checkpoint proteins by cEPA. To study the mechanism of cEPA-induced cell cycle block further in comparison with or without the $\mathrm{p} 53$ gene, the protein expression of p53-upstream and p53-downstream signaling pathways was investigated by Western blotting (Fig. 3). The expression level of the related proteins for DNA damage checkpoint (i.e., p53-upstream signaling pathways) with the $\mathrm{LD}_{50}$ value of cEPA treatment in NALM-6 cells is shown in Fig. 3A. A recent report demonstrated that the uncoupling of 
(A)

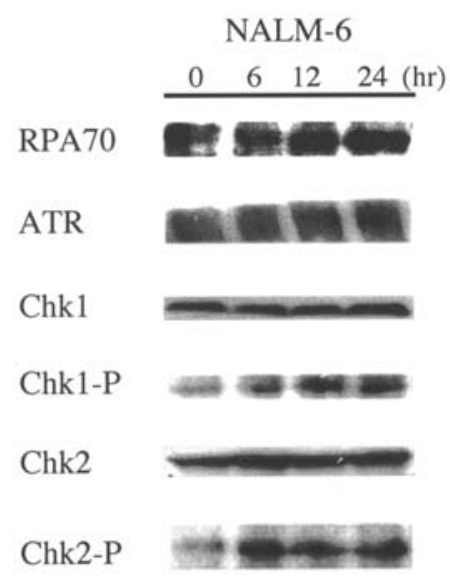

(B)

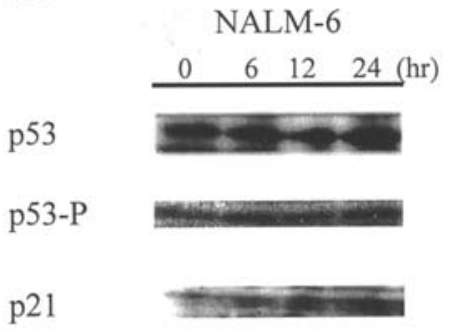

$\operatorname{Cdc} 25 \mathrm{~A}$

$\beta$-actin

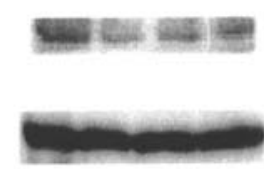

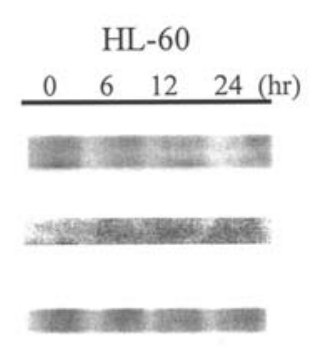

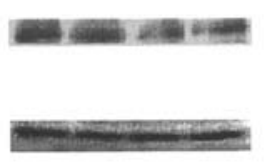

Figure 3. Expression of checkpoint proteins after cEPA treatment induction in human leukemia cell lines. (A) NALM-6 cells were treated with the $\mathrm{LD}_{50}$ value of cEPA $(37.5 \mu \mathrm{M})$ to investigate the protein expression of the p53-upstream signaling pathway such as RPA70, ATR, Chk1, Chk1-P (phosphorylated form of Chk1-Ser345), Chk2 and Chk2-P (phosphorylated form of Chk2-Thr68) by Western blotting for the indicated time. (B) NALM-6 cells and HL-60 cells were incubated with the $\mathrm{LD}_{50}$ values of cEPA (i.e., 37.5 and $12.5 \mu \mathrm{M}$, respectively) for the indicated time, and then collected to analyze the expression of p53-downstream targets such as p53, p53-P (phosphorylated form of p53-Ser15), p21, Cdc25A and $\beta$-actin (control) by Western blotting.

helicase and pol activities, which leads to the formation of long regions of RPA (replication protein A)-coated singlestranded DNA (ssDNA) at replication forks, is necessary for ATR (ataxia-telangiectasia mutated- and Rad3-related protein kinase) checkpoint signaling in Xenopus extracts (35). RPA70 (70 kDa subunit of RPA) and ATR were timedependently increased by cEPA treatment. Although the expression levels of Chk1 and Chk2, which regulate the DNA replication checkpoint, had no influence, these proteins were clearly phosphorylated (Fig. 3A). The expression of these proteins on the cancer cell line HL-60 of p53-null mutant had the same tendency as that on NALM- 6 cells of p53 wild-type (data not shown).

Cell cycle control is the major regulatory mechanism of cell growth (36). The cell cycle is regulated by the coordinated

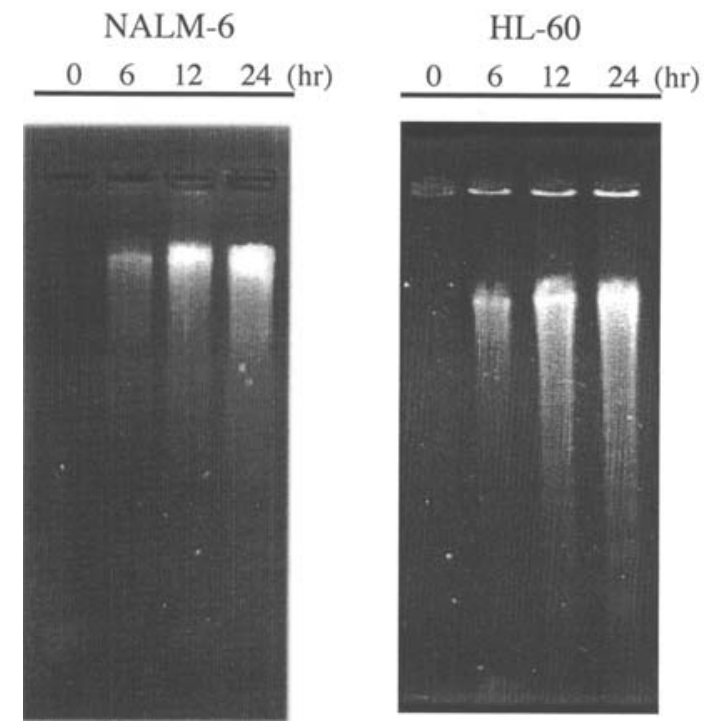

Figure 4. Effect of cEPA on the induction of apoptosis. Nucleosomal DNA fragmentation of NALM-6 cells and HL-60 cells after exposure to the $\mathrm{LD}_{50}$ values of cEPA (i.e., 37.5 and $12.5 \mu \mathrm{M}$, respectively). Following cell lysis, total DNA was extracted and analyzed by agarose gel electrophoresis.

action of cyclin-dependent kinases (cdks) in association with their specific regulatory cyclin proteins. Cdk inhibitors, including p21, also contribute to the regulation of cell cycle progression by controlling cdk activity. p21 inhibits a wide variety of cyclin-cdk complexes in vitro, including cdk4 and cdk2 complexes which are activated early in the G1 phase $(37,38)$, and overexpression of these proteins blocks the progression of cells through G1 (39). p53 plays the central role in the G1 phase arrest because it is known to be an upstream regulator of $\mathrm{p} 21$, a cdk inhibitor. To explore the mechanisms of cEPA-induced cell cycle arrest, the expression of p53 protein and cdk inhibitor, p21 protein, was examined by Western blotting because these inhibitory proteins play a negative regulatory role in the $\mathrm{G} 1$ phase, and disappearance of these inhibitory activities is associated with G1/S progression induced by a number of mitogens $(40,41)$. When NALM-6 cells were incubated with $37.5 \mu \mathrm{M}$ cEPA, the $\mathrm{p} 53$ protein expression did not change, but the expression of phosphorylated-p53 markedly increased time-dependently (Fig. 3B). The 21 protein expression also increased in parallel to the phosphorylated-p53 protein expression. Since cEPA-induced cell cycle arrest showed time dependence, these results suggested that p53 and p21 proteins might be held in a state of active repression in cells that have stalled DNA replication forks, and were expressed with cell cycle arrest. On the other hand, HL-60, which is a p53-null mutant, could not detect the protein expression of not only p53 and phosphorylated-p53, but also p21, suggesting that $\mathrm{p} 21$ protein was not expressed because of the absence of phosphorylated-p53 protein.

The current concept of a cell cycle checkpoint response places the regulatory kinase Chk1/2 upstream from Cdc $25 \mathrm{~A}$ (42). Cdc25A is involved in the G1 to intra-S phase checkpoint, and the level reaches a maximum in the end of the G1 phase and the early S phase (43). Both NALM-6 and HL-60 cells had blocked Cdc25A protein expression by cEPA treatment. Cdc25A dephosphorylates and activates the cyclin E-cdk2 
(A) p53-wild type (NALM-6 cells)

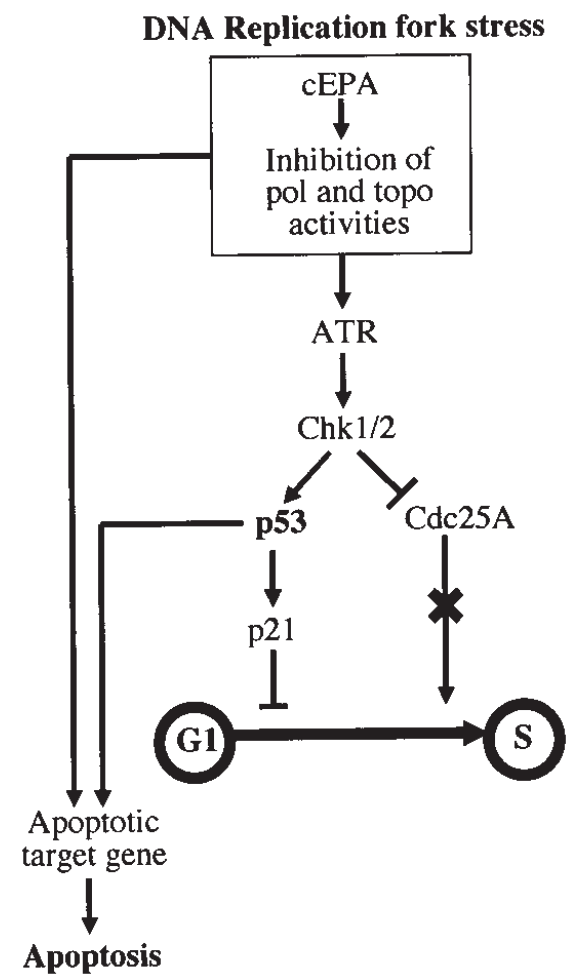

(B) p53-null (HL-60 cells)

DNA Replication fork stress

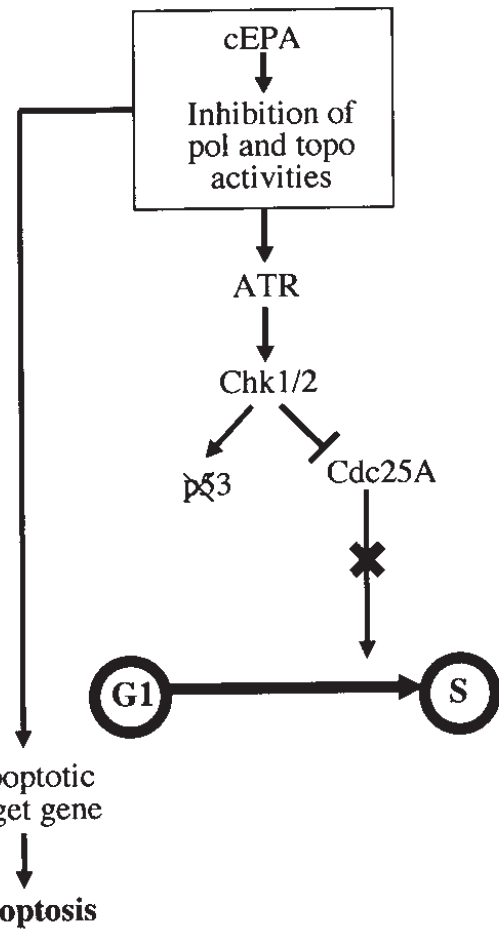

Figure 5. Role of p53 in the prevention of cell cycle arrest and cell death by cEPA. (A) DNA replication fork inhibitors such as cEPA activate p53 that triggers p21 activation and prevents the cell cycle from G1 to S phase development. (B) The lack of p53 leads to cell cycle arrest in the G1 phase by Cdc25A and results in apoptosis of virtually the entire cell population.

complex that is activated during $\mathrm{G} 1$ phase (44), and it is reported that reduction of Cdc25A contributes to cyclin E-cdk2 inhibition and G1 arrest (45). Therefore, G1 transition arrest by cEPA showed a relationship to Cdc25A protein suppression.

Effects of cEPA on apoptosis. To examine whether the decrease in cell numbers caused by cEPA was due to apoptosis, DNA fragmentation was analyzed by electrophoresis. DNA ladder formation was detected at $6 \mathrm{~h}$ and time-dependently increased in both NALM- 6 and HL-60 cells treated with the $\mathrm{LD}_{50}$ value of cEPA (Fig. 4). In cell cycle analysis, cEPA-treated cells were in the sub-G1 phase (data not shown). These results suggested that the effect of cEPA must involve a combination of growth arrest and cell death, and apoptosis by cEPA led to both a p53dependent pathway and p53-independent pathway [e.g., cell death receptor, reactive oxygen species (ROS), and so on].

\section{Discussion}

In this report, the mechanisms by which cEPA suppresses cancer cell growth were investigated, and it was revealed that the inhibition of mammalian pol and human topo activities by cEPA influenced not only cell proliferation but also cell cycle arrest in the G1 phase. It is considered that the inhibition of pol and topo activities could be 'DNA replication stress' (Fig. 5). Upon perturbation of DNA synthesis by inhibitors of DNA replication such as cEPA, the rate of DNA unwinding becomes greater than the rate of DNA synthesis, leading to functional uncoupling of topos from replicative pols. As shown in Fig. 5, it is suggested that this results in the creation of large regions of unwound ssDNA and leads to the accumulation of RPA, ATRIP (ATR-interacting protein) and ATR on chromation (46). As unwinding occurs, the pol $\alpha$-primase complex begins DNA synthesis on the unwound DNA. The induced proximity of ATR at primer/template junctions then must lead to Chk1/2 phosphorylation (47).

Cell cycle arrest in the G1 phase by cEPA, which is a selective inhibitor of mammalian pols and topos, is considered to be induced to the $\mathrm{p} 53 / \mathrm{p} 21$ pathway from the ATR-Chk $1 / 2$ signaling pathway in p53-wild cells such as NALM-6 (Fig. 5A). On the other hand, ectopic expression of Chk1/2 from the p53-upstream signaling pathway could prevent the phosphorylation of $\mathrm{Cdc} 25 \mathrm{~A}$, and then store the $\mathrm{G} 1$ phase arrest in p53-null cells such as HL-60 (Fig. 5B).

Since the conjugated form of EPA (i.e., cEPA) is a 2-fold stronger pol inhibitor than normal EPA, cEPA consists of conjugated double bonds, and this structural feature may stimulate the inhibition of pol activities (19). Since cEPA did not influence the proliferation of normal cells (data not shown), cEPA should be considered the lead compound of potentially useful cancer chemotherapy agents.

\section{Acknowledgements}

We are grateful for the donations of calf pol $\alpha$, rat pol $\beta$, human pol $\gamma$, and human pols $\delta, \varepsilon$ by Dr M. Takemura of Tokyo University of Science (Tokyo, Japan), Dr A. Matsukage of Japan Women's University (Tokyo, Japan), Dr M. Suzuki of 
Nagoya University (Nagoya, Japan), and Dr K. Sakaguchi of Tokyo University of Science (Chiba, Japan), respectively. This study was supported in part by a Grant-in-aid for KobeGakuin University Joint Research (A), and 'Academic Frontier' Project for Private Universities: matching fund subsidy from MEXT (Ministry of Education, Culture, Sports, Science and Technology), 2006-2010, (H.Y. and Y.M.). Y.M. acknowledges Grants-in-aid from the Nakashima Foundation (Japan).

\section{References}

1. Kornberg A and Baker TA: DNA replication. Chapter 6. 2nd edition. W.D. Freeman and Co., New York, pp197-225, 1992.

2. Wang JC: DNA topoisomerases. Annu Rev Biochem 65: 635-691, 1996.

3. Mizushina Y, Yagi H, Tanaka N, Kurosawa T, Seto H, Katsumi K, Onoue M, Ishida H, Iseki A, Nara T, Morohashi K, Horie T, Onomura Y, Narusawa M, Aoyagi N, Takami K, Yamaoka M, Inoue Y, Matsukage A, Yoshida S and Sakaguchi K: Screening of inhibitor of eukaryotic DNA polymerases produced by microorganisms. J Antibiot (Tokyo) 49: 491-492, 1996.

4. Mizushina Y, Tanaka N, Yagi H, Kurosawa T, Onoue M, Seto H, Horie T, Aoyagi N, Yamaoka M, Matsukage A, Yoshida S and Sakaguchi K: Fatty acids selectively inhibit eukaryotic DNA polymerase activities in vitro. Biochim Biophys Acta 1308: 256-262, 1996.

5. Mizushina Y, Yoshida S, Matsukage A and Sakaguchi K: The inhibitory action of fatty acids on DNA polymerase $B$. Biochim Biophys Acta 1336: 509-521, 1997.

6. Mizushina Y, Sugawara F, Iida A and Sakaguchi K: Structural homology between DNA binding sites of DNA polymerase $B$ and DNA topoisomerase II. J Mol Biol 304: 385-395, 2000.

7. Fernandez E, Chatenoud L, La Vecchia C, Negri E and Franceschi S: Fish consumption and cancer risk. Am J Clin Nutr 70: 85-90, 1990.

8. Lindner MA: A fish oil diet inhibits colon cancer in mice. Nutr Cancer 15: 1-11, 1991.

9. Reddy BS, Burill C and Rigotty J: Effect of diets high in omega-3 and omega- 6 fatty acids on initiation and postinitiation stages of colon carcinogenesis. Cancer Res 51: 487-491, 1991.

10. Hirose M, Masuda A, Ito N, Kamano K and Okuyama H: Effects of dietary perilla oil, soybean oil and safflower oil on 7,12-dimethylbenz(a) anthracene (DMBA) and 1,2-dimethylhydrazine (DMH)-induced mammary gland and colon carcinogenesis in female SD rats. Carcinogenesis 11: 731-735, 1990

11. Iigo M, Nakagawa T, Iwahori Y, Asamoto M, Yazawa K, Araki E and Tsuda $\mathrm{H}$ : Inhibitory effects of docosahexaenoic acid on colon carcinoma 26 metastasis to the lung. Br J Cancer 75: 650-655, 1997.

12. Iwamoto S, Senzaki H, Kiyozuka Y, Ogura E, Takada H, Hioki K and Tsubura A: Effects of fatty acids on liver metastasis of ACL15 rat colon cancer cells. Nutr Cancer 31: 143-150, 1998

13. Ha YL, Grimm NK and Pariza MW: Anticarcinogens from fried ground beef: heat-altered derivatives of linoleic acid. Carcinogenesis 8: 1881-1887, 1987.

14. Park HS, Ryu JH, Ha YL and Park JH: Dietary conjugated linoleic acid (CLA) induces apoptosis of colonic mucosa in 1,2dimethylhydrazine-treated rats: a possible mechanism of the anticarcinogenic effect by CLA. Br J Nutr 86: 549-555, 2001.

15. Shultz TD, Chew BP, Seaman WR and Luedecke LO: Inhibitory effect of conjugated dienoic derivatives of linoleic acid and $\beta$-carotene on the in vitro growth of human cancer cells. Cancer Lett 63: 125-133, 1992.

16. Kelly GS: Conjugated linoleic acid: a review. Altern Med Rev 6: 367-382, 2001

17. Lopez A and Gerwick WH: Two new icosapentaenoic acids from the temperate red seaweed Ptilota filicina J. Agardh. Lipids 22: 190-194, 1987.

18. Mikhailova MV, Bemis DL, Wise ML, Gerwick WH, Norris JN and Jacobs RS: Structure and biosynthesis of novel conjugated polyene fatty acids from the marine green alga Anadyomene stellata. Lipids 30: 583-589, 1995.

19. Yonezawa Y, Tsuzuki T, Eitsuka T, Miyazawa T, Hada T, Uryu K, Murakami-Nakai C, Ikawa H, Kuriyama I, Takemura M, Oshige M, Yoshida H, Sakaguchi K and Mizushina Y: Inhibitory effect of conjugated eicosapentaenoic acid on human DNA topoisomerases I and II. Arch Biochem Biophys 435: 197-206, 2005.
20. Kanno S, Higurashi A, Watanabe Y, Shouji A, Asou K and Ishikawa M: Susceptibility to cytosine arabinoside (Ara-C)induced cytotoxicity in human leukemia cell lines. Toxicol Lett 152: 149-158, 2004

21. Helrich K: Acids (poly-unsaturated) in oil and fats. In: Official Methods of Analysis of the Association of Official Analytical Chemists. Association of Official Analytical Chemists, Arlington, pp960-963, 1990.

22. Pitt GAJ and Morton RA: Chem. Fats Other Lipids 4: 227-278, 1957.

23. Tamai K, Kojima K, Hanaichi T, Masaki S, Suzuki M, Umekawa $H$ and Yoshida S: Structural study of immunoaffinitypurified DNA polymerase $\alpha$-DNA primase complex from calf thymus. Biochim Biophys Acta 850: 263-273, 1988.

24. Date T, Yamaguchi M, Hirose F, Nishimoto Y, Tanihara K and Matsukage A: Expression of active rat DNA polymerase B in Escherichia coli. Biochemistry 27: 2983-2990, 1988.

25. Yonezawa Y, Kuriyama I, Fukuoh A, Muta T, Kang D, Takemura M, Kato I, Yoshida $\mathrm{H}$ and Mizushina $\mathrm{Y}$ : Inhibitory effect of coenzyme Q on eukaryotic DNA polymerase $\gamma$ and DNA topoisomerase II activities on the growth of a human cancer cell line. Cancer Sci 97: 716-723, 2006.

26. Oshige M, Takeuchi R, Ruike R, Kuroda K and Sakaguchi K: Subunit protein-affinity isolation of Drosophila DNA polymerase catalytic subunit. Protein Expr Purif 35: 248-256, 2004.

27. Lui LF and Miller KG: Eukaryotic DNA topoisomerases: two forms of type I DNA topoisomerases from HeLa cell nuclei. Proc Natl Acad Sci USA 78: 3487-3491, 1981.

28. Mosmann T: Rapid colorimetric assay for cellular growth and survival: application to proliferation and cytotoxicity assays. J Immunol Methods 65: 55-63, 1983.

29. Ikegami S, Taguchi T, Ohashi M, Oguro M, Nagano $\mathrm{H}$ and Mano Y: Aphidicolin prevents mitotic cell division by interfering with the activity of DNA polymerase- $\alpha$. Nature 275: 458-460, 1978.

30. Izuta S, Saneyoshi M, Sakurai T, Suzuki M, Kojima K and Yoshida S: The 5'-triphosphates of 3'-azido-3'-deoxythymidine and 2', 3'-dideoxynucleosides inhibit DNA polymerase $\gamma$ by different mechanisms. Biochem Biophys Res Commun 179: 776-783, 1991

31. Murakami-Nakai C, Maeda N, Yonezawa Y, Kuriyama I, Kamisuki S, Takahashi S, Sugawara F, Yoshida H, Sakaguchi K and Mizushina Y: The effects of dehydroaltenusin, a novel mammalian DNA polymerase $\alpha$ inhibitor, on cell proliferation and cell cycle progression. Biochim Biophys Acta 1674: 193-199, 2004.

32. Nishida K, Seto M and Ishida R: Different susceptibilities of postmitotic checkpoint-proficient and -deficient Balb/3T3 cells to ICRF-193, a catalytic inhibitor of DNA topoisomerase II. Jpn J Cancer Res 92: 193-202, 2001.

33. Woo RA and Poon RY: Cyclin-dependent kinases and S phase control in mammalian cells. Cell Cycle 2: 316-324, 2003.

34. Pines $\mathrm{J}$ and Hunter T: Isolation of a human cyclin cDNA evidence for cyclin mRNA and protein regulation in the cell cycle and for interaction with p34 cdc2. Cell 58: 833-846, 1989.

35. Byun TS, Pacek M, Yee MC, Walter JC and Cimprich KA: Functional uncoupling of MCM helicase and DNA polymerase activities activates the ATR-dependent checkpoint. Genes Dev 19: 1040-1052, 2005.

36. Rittling SR, Brooks KM, Cristofalo VJ and Baserga R: Expression of cell cycle-dependent genes in young and senescent WI-38 fibroblasts. Proc Natl Acad Sci USA 83: 3316-3320, 1986.

37. Matsushime H, Ewen ME, Strom DK, Kato JY, Hanks SK, Roussel MF and Sherr CJ: Identification and properties of a typical catalytic subunit (p34PSK-J3/cdk4) for mammalian D type G1 cyclins. Cell 71: 323-334, 1992.

38. Meyerson $\mathrm{M}$ and Harlow E: Identification of G1 kinase activity for cdk6, a novel cyclin D partner. Mol Cell Biol 14: 2077-2086, 1994.

39. Hunter T and Pines J: Cyclins and cancer. II: Cyclin D and CDK inhibitors come of age. Cell 79: 573-582, 1994.

40. Toyoshima $\mathrm{H}$ and Hunter T: p27, a novel inhibitor of G1 cyclinCdk protein kinase activity, is related to p21. Cell 78: 67-74, 1994.

41. Xiong Y, Hannon GJ, Zhang H, Casso D, Kobayashi R and Beach D: p21 is a universal inhibitor of cyclin kinases. Nature 366: 701-704, 1993

42. Falck J, Mailand N, Syljuasen RG, Bartek J and Lukas J: The ATM-Chk2-Cdc25A checkpoint pathway guards against radioresistant DNA symtnesis. Nature 410: 842-847, 2001. 
43. Galaktionov K and Beach D: Specific activation of cdc25 tyrosine phosphatase by B-type cyclins: evidence for multiple roles of mitotic cyclins. Cell 67: 1181-1194, 1991.

44. Blomberg I and Hoffmann I: Ectopic expression of Cdc25A accelerates the $\mathrm{G}(1) / \mathrm{S}$ transition and leads to premature activation of cyclin E- and cyclin A-dependent kinases. Mol Cell Biol 19: 6183-6194, 1999.

45. Sandhu C, Donovan J, Bhattacharya N, Stampfer M, Worland P and Slingerland J: Reduction of Cdc25A contributes to cyclin E1-Cdk2 inhibition at senescence in human mammary epithelial cells. Oncogene 19: 5314-5323, 2000.
46. Zou L and Elledge SJ: Sensing DNA damage through ATRIP recognition of RPA-ssDNA complexes. Science 300: 1542-1548, 2003.

47. Melo J and Toczyski D: A unified view of the DNA-damage checkpoint. Curr Opin Cell Biol 14: 237-245, 2002. 